We wish to thank Miss H. P. Meggs for preparing the drawing for Fig. 1.

National Standards Laboratory,

E. H. MERCER.

Council for Scientiflc and Industrial Research, Sydney.

Division of Industrial Chemistry,

A. L. G. REES.

Council for Scientific and Industrial Research, Melbourne. Feb. 7 .

Woods, Proc. Roy. Soc., A, 168, 76 (1938).

2 Speakman and Stott, $\vec{J}$. Text. Inst., 22, T.339 (1931).

- Mercer, Nature, 155, 573 (1945).

- Speakman, ChamberIain and Menkart, J. Text. Inst., 36, T.91_(1945)

S Speakman and Menkart, Nature, 156, 143 (1945).

\section{Formation of Polymers in Textile Fibres}

WHEN wool fibres are exposed to the vapour of ethylene sulphide and water at $50^{\circ} \mathrm{C}$., polymerization takes place within the fibres their elastic properties are modifled, and felting is prevented durin subsequent working in soap golution ${ }^{1}$. Similar reactions take place wicrylate, if the fibres are flrst impregnated with ammonium persulphate acrylate, if the fibres are furst impregnated with ammonium persulphate
as a catalyst ${ }^{2}$. It would obviously be a convenience, in practice, if as a catalyst ${ }^{2}$. It would obviously be a convenience, in practice, if polymers could be formed within wool flbres by treatment with aqueous dispersions of the corresponding monomers instead of with the mixed vapours of water and monomer. A solution to the problem has been found in the use of immobile cataly

in conjunction with hydrogen peroxide ${ }^{3}$. in 0.2 per cent ferrous sulphate solution, squeezed, dried and then treated with a mixture of water (200 c.c.) and either methyl methacrylate $(10$ c.c.) or acrylonitrile $(10$ c.c.) for one or two hours a $95^{\circ}-100^{\circ} \mathrm{C}$. in presence and absence of hydrogen peroxide $(0.03$ pe cent). For reference purposes, one pattern was treated with methy methacrylate and water in absence of both iron and hydrogen per oxide. After treatment the patterns were washed well in running water, conditioned, and re-weighed to determine the gain in weight due to deposition of polymer. The patterns were then hand-milled are given in the table.

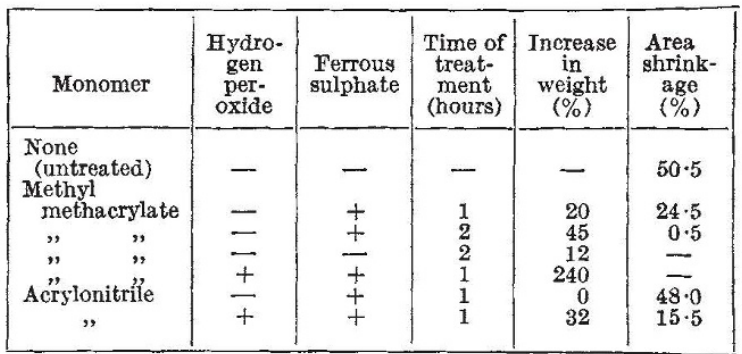

Iron alone appears to promote polymerization of methyl methacrylate, although the reaction is very much more rapid in presence of hydrogen peroxide, which is essential to the polymerization of acrylonitrile under the above conditions. The unshrinkability conferred on the fiannel by the above treatments seems to be due to the formation and deposition of polymer within the flbres, though some deposition of polymer on the outside of the flbres is unavoidable, especially when large amounts are formed. Reactions such as the preceding are important not merely in providing a simple method of amples of a general method of modifying the properties of textfle flbres.

One of us (M. L.) Is indebted to the International Wool Secretariat and the Australian Wool Board for grants which enabled him to take part in the investigation.

Textile Chemistry Laboratory,

$$
\text { M. LIPSON. }
$$

J. B. SPEAKMAN.

University, Ieeds.

March 2.

${ }^{1}$ Barr and Speakman, J. Soc. Dyers and Col., 60, 238 (1944).

Speakman and Barr, Brit. Pat., 559,787 (1944).

Haber and Weiss, Naturwiss., 20, 948 (1932). Baxendale, Evans and Park, Trans. Faraday Soc., in the press.

\section{A Bent Pebble}

DR. JosePF NEEDHAM, of the Sino-British Sclence Co-operation Office, directed my attention to an experiment by Lord Rayleigh on a piece of crown glass under long-continued strain ${ }^{2}$. Lord Rayleigh' results suggest further consideratton of a curiously curved, smal pebble of a fne-grained quartzose sandstone briefly described elsewhere. Figs. 1 and 2 illustrate almost diametrically opposite aspects of the pebble. By turning the specimen downward from the position shown in Fig. 2 around a horizontal axis through an angle of about $35^{\circ}$, the view represented by Fig. 3 is obtained. These illustrations
show that the pebble is equally well-rounded on all sides, characteristio of all water-worn pebbles of the lenticular shape which it would have assumed had it not been folded across the middle. A slight, abnormal inflation is noticeable in Fig. 1 on the concave side along the middle

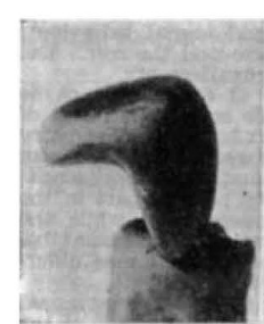

(1)

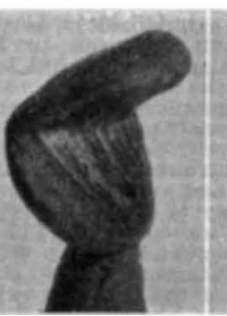

(2)

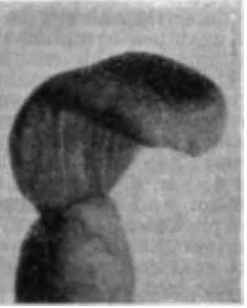

(3) zone where the curvature is the sharpest, apparently due to a localization of compression. This, coupled with the gently concave 'sky-line' seen on the top in Fig. 3 showing the transverse curvature of an anticlastic surface developed on the convex side, affords indisputable evidence for a bending at least partly of elastic nature. Such bending could only have taken place after the lenticular pebble had been formed; for otherwise the anticlastic curvature could not have escaped erosion. An oriented chip detached from the lower part of the left-upper corner in Fig. 3 revealed, under the microscope, that the bedding planes in the original rock agreed in direction with the coarse striations present, on the concave side of the pebble visible in Figs. 2 and 3 ; and further, it will be noticed that these coarse striations, that is, weathered traces of bedding planes in the original rock, are rendered askew as they are seen on the re-entrant faces, obviously by bending around an axis which runs obliquely to the bedding plane. Finally, no such trace of dynamic metamorphism is detectable either macroscopically or microscopically, as would be usually expected to oceur when the rock has undergone so severe a macroscopic deformation. Even if a structural predisposition in the original rock conducive to such a fantastic shaping be assumed, an inconceivably intricate process would still be required to produce the sculpturing and erosion. It may thus be safely concluded that we are here dealing with a discould be permitted a place in modern geology.

This pebble was found in a gravel closely connected to a terminal moraine on the eastern side of the mountain-range about twenty miles south-west of $K$ weilin. The small vanished glacier, estimated to have a thickness of 240-300 $\mathrm{ft}$, at its maximum, had its sources and upper course in a pre-Devonian terrain of a regularly bedded series of shales,
slates and sandstones, including the type of rock of which the pebble is composed, and its lower reach in a fleld of Devonian and postDevonian limestones. Repeated searches were made across the strike of these formations, especially along the junction between the Devonian and pre-Devonian strata, with the view of locating the possible occur. rence of a bed of conglomerate containing the type of deformed pebble under consideration or of any zone of locally intensified disturbance involving contorted bands of the quartzose sandstone. None of these was found; nor are they likely to occur considering the nature of the terrain.

These circumstances, together with the evidence yielded by the pebble itself, seem to remove any doubt that the pebble was in some way strained by a load due to the glacier. A planed and polished area is seen in Fig. I on the outer face of that portion of the pebble which is bent over to the left. This polished area is marked by a few faint strio running perpendicular to the edge on the right produced by bending. While it is admittedly unsound to attach too much significance to these details, they suggest that deformation was due to holding fast half of the peble, as might happen by jamming in a crack or the bed-rock or in the glacier fully charged with rock debris, ice.

\section{Geological Institute, \\ Chungking.}

Nature, 145, 29 (1940).

\section{Uitrasonic Velocities in Rock Sections}

DORING the course of an investigation relating to the elastic properties of different types of sedimentary and igneous rocks employing the uitrasonic wedge method recently developed by Bhagavantam and Bhimasenachar ${ }^{1}$, I have obtained some results which are likely to be of great importance from two or three different aspects. A preliminary report is accordingly made here.

plates perpendicular to three mutually orthogonal directions are Plates perpendicuiar to three mutually orthogonal directions are
cut from each rock under investigation. Velocities of longitudinal ultrasonic waves with frequencies ranging from 1 to 10 megacycles ultrasonic waves with frequencies ranging from 1 to 10 megacycles along the thickness directions are determined. The results for a few selected samples are given in the accompanying table. Column 2 case of sedimentary rocks and to that of easy breakage in the case case of sedimentary rocks and to that of easy breakage in the case of others. Columns 3 and 4 refer to plates normal to
Rock

Bhima limestone

Jubbalpore marble

Gneiss

Pink Hyderabad

granite

Dunite

Deccan trai

Eclogite

$6 \cdot 20$ km
$6 \cdot 46$
$6 \cdot 29$
$6 \cdot 62$
$7 \cdot 84$
$8 \cdot 27$
$8 \cdot 61$
$7 \cdot 84$

(2)

.4

$6 \cdot 62$

$8 \cdot 27$

$7 \cdot 8$
(3)

$5 \cdot 14 \mathrm{~km} . / \mathrm{sec}$.
$5 \cdot 57$
$5 \cdot 48$

6.53

$6 \cdot 91$

$6 \cdot 97$

$7 \cdot 84$
(4)

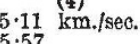

$5 \cdot 57$
$4 \cdot 32$

$4 \cdot 80$

$4 \cdot 58$ 